\title{
Mortality risk assessment in Spain and Italy, insights of the HOPE COVID-19 registry
}

\author{
Iván J. Núñez-Gil ${ }^{1}$. Cristina Fernández-Pérez ${ }^{9,24}$. Vicente Estrada ${ }^{1} \cdot$ Víctor M. Becerra-Muñoz ${ }^{2}$. \\ Ibrahim El-Battrawy ${ }^{3}$. Aitor Uribarri ${ }^{4} \cdot$ Inmaculada Fernández-Rozas ${ }^{5}$. Gisela Feltes ${ }^{6} \cdot$ María C. Viana-Llamas $^{7}$. \\ Daniela Trabattoni ${ }^{8}$. Javier López-País ${ }^{9} \cdot$ Martino Pepe $^{10} \cdot$ Rodolfo Romero $^{11} \cdot$ Alex F. Castro-Mejía ${ }^{12}$. \\ Enrico Cerrato ${ }^{13,27}$. Thamar Capel Astrua ${ }^{14}$. Fabrizio D'Ascenzo ${ }^{15}$. Oscar Fabregat-Andres ${ }^{16}$. José Moreu ${ }^{17}$. \\ Federico Guerra ${ }^{18}$. Jaime Signes-Costa ${ }^{19}$. Francisco Marín ${ }^{20,26}$. Danilo Buosenso ${ }^{21}$. Alfredo Bardaji ${ }^{22}$. \\ Sergio Raposeiras-Roubín ${ }^{23}$. Javier Elola ${ }^{24}$. Ángel Molino - Juan J. Gómez-Doblas ${ }^{2}$ - Mohammad Abumayyaleh ${ }^{3}$. \\ Álvaro Aparisi ${ }^{4} \cdot$ María Molina $^{5} \cdot$ Asunción Guerri $^{6} \cdot$ Ramón Arroyo-Espliguero $^{7} \cdot$ Emilio Assanelli $^{8}$. \\ Massimo Mapelli ${ }^{8,25}$. José M. García-Acuña ${ }^{9} \cdot$ Gaetano Brindicci $^{10}$ - Edoardo Manzone ${ }^{11} \cdot$ María E. Ortega-Armas $^{12}$. \\ Matteo Bianco ${ }^{13}$. Chinh Pham Trung ${ }^{14}$. María José Núñez ${ }^{1}$ Carmen Castellanos-Lluch ${ }^{19}$. Elisa García-Vázquez ${ }^{20,26}$. \\ Noemí Cabello-Clotet ${ }^{1} \cdot$ Karim Jamhour-Chelh $^{23} \cdot$ María J. Tellez $^{1} \cdot$ Antonio Fernández-Ortiz $^{1} \cdot$ Carlos Macaya $^{1}$ on \\ behalf of HOPE COVID-19 Investigators
}

Received: 11 May 2020 / Accepted: 15 October 2020 / Published online: 9 November 2020

(c) Società Italiana di Medicina Interna (SIMI) 2020

\begin{abstract}
Recently the coronavirus disease (COVID-19) outbreak has been declared a pandemic. Despite its aggressive extension and significant morbidity and mortality, risk factors are poorly characterized outside China. We designed a registry, HOPE COVID-19 (NCT04334291), assessing data of 1021 patients discharged (dead or alive) after COVID-19, from 23 hospitals in 4 countries, between 8 February and 1 April. The primary end-point was all-cause mortality aiming to produce a mortality risk score calculator. The median age was 68 years (IQR 52-79), and 59.5\% were male. Most frequent comorbidities were hypertension (46.8\%) and dyslipidemia (35.8\%). A relevant heart or lung disease were depicted in $20 \%$. And renal, neurological, or oncological disease, respectively, were detected in nearly $10 \%$. Most common symptoms were fever, cough, and dyspnea at admission. 311 patients died and 710 were discharged alive. In the death-multivariate analysis, raised as most relevant: age, hypertension, obesity, renal insufficiency, any immunosuppressive disease, 02 saturation $<92 \%$ and an elevated $\mathrm{C}$ reactive protein (AUC $=0.87$; Hosmer-Lemeshow test, $p>0.999$; bootstrap-optimist: 0.0018). We provide a simple clinical score to estimate probability of death, dividing patients in four grades (I-IV) of increasing probability. Hydroxychloroquine $(79.2 \%)$ and antivirals (67.6\%) were the specific drugs most commonly used. After a propensity score adjustment, the results suggested a slight improvement in mortality rates (adjusted-OR $\mathrm{OR}_{\text {hydroxychloroquine }} 0.88 ; 95 \%$ CI 0.81-0.91, $p=0.005$; adjusted-OR antiviral $0.94 ; 95 \%$ CI $0.87-1.01 ; p=0.115$ ). COVID-19 produces important mortality, mostly in patients with comorbidities with respiratory symptoms. Hydroxychloroquine could be associated with survival benefit, but this data need to be confirmed with further trials. Trial Registration: NCT04334291/EUPAS34399.
\end{abstract}

Iván J. Núñez-Gil, Cristina Fernández-Pérez and Vicente Estrada contributed equally to this work.

The members of Hope COVID-19 investigators, scientific committee and Collaborators are listed in Supplementary appendix.

Electronic supplementary material The online version of this article (https://doi.org/10.1007/s11739-020-02543-5) contains supplementary material, which is available to authorized users.

Extended author information available on the last page of the article 
Keywords COVID- $19 \cdot$ Mortality $\cdot$ Score $\cdot$ Registry $\cdot$ Prognosis

\section{Introduction}

Recently, a severe outbreak of a newly discovered coronavirus (SARS-CoV-2, previously 2019-nCoV) causing a zoonotic disease named coronavirus disease 2019 (COVID19) [1] has been declared a pandemic by WHO [2]. With a broad spectrum of symptoms, most of the available data has been provided based on Chinese patients since it was first reported in December 2019 [1, 3]. In these reports, although most patients were deemed to be asymptomatic or have mild upper respiratory tract involvement, others developed a severe respiratory condition, including bilateral pneumonias, sepsis, distress and other potentially fatal complications, but usually with relatively low in-hospital death rate $(<5 \%)$ [4].

Consequently, after demonstrating an efficient person-toperson transmission, several questions remain unanswered about COVID-19, including if the behavior of the disease is different outside the Asian breed and an adequate precise treatment. Furthermore, the very aggressive extension of the infection in several countries, more so than in China, with an increasing number of confirmed cases in most countries worldwide, is responsible for a significant morbi-mortality and has motivated the implementation of measures at an international level with a great impact on people's way of life on a worldwide level.

In fact, according to figures updated on 27 April 2020, the WHO has recognized a relevant mortality of over 2,858,635 confirmed cases with 196,295 confirmed deaths in 213 countries or territories with cases [5].

Moreover, this condition currently threatens many countries with the collapse of their health systems, producing serious logistical problems due to extensive affectation of the population which can worsen the prognosis of those primarily affected by COVID-19 as well as other patients with different pathologies and who may experience difficulty accessing healthcare.

Here we analyze the clinical profile, presentation and the influence of previous treatments in patients hospitalized due to COVID-19, primarily focusing on mortality and producing a risk score designed to facilitate the allocation of resources.

\section{Methods}

The study is investigator-initiated and approved by the ethics committee of the promoting center, National Drug Agency (AEMPs classification EPA-0D) and by institutional board or local committees. Written informed consent was waived due to the nature of the anonymized registry and the severity of the situation. Data were analyzed with the support of an independent specialized foundation (Institute for the Improvement of Health Care, Madrid, Spain, IMAS), serving as statistical core. All local principal investigators reviewed the draft and vouch for the accuracy and veracity of data. A list of participating hospitals, investigators, collaborators, protocol and definitions are available in the appendix.

\section{Study design and participation criteria}

HOPE-COVID-19 (Health Outcome Predictive Evaluation for COVID-19, NCT04334291) is an international initiative with no conflicts of interest. It is designed as a retrospective cohort registry, a real life, all-comers type, with no financial remuneration.

All patients receiving attention in any health center with in-hospital beds, who have been discharged or have died at the time of the evaluation who had a positive COVID-19 test (throat swab samples were obtained from patients at admission and tested using real-time reverse transcriptase-polymerase chain reaction assays according to the WHO recommendation) or if their attending physicians considered them highly likely to have presented the infection, are eligible.

An online database is presented in electronic format to be filled in by each participating center (https://www.HopeP rojectMD.com). The data presented here corresponds to the HOPE COVID-19 Registry predefined interim analysis with a cutoff performed on April $2^{\text {nd }}$.

\section{Study outcomes}

We considered as primary end-point all-cause mortality. Invasive mechanical ventilation, and other clinically relevant events were recorded as secondary end-points (noninvasive mechanical ventilation, prone, respiratory insufficiency, heart failure, renal failure, upper respiratory tract involvement, pneumonia, sepsis, systemic inflammatory response syndrome, clinically relevant bleeding, hemoptysis and embolic events). Events were allocated following local researchers' criteria.

\section{Statistical analysis}

Qualitative variables are presented as their frequencies and quantitative data as the mean and standard deviation or median and interquartile range, as appropriate, for all cohorts (descriptive and analytical). Due to heterogeneity among countries regarding clinical features, for death-risk assessment purposes, only patients from Italy and Spain 
were considered. Since the clinical profile was reasonably similar, a country effect was discarded at this level, therefore these countries made up the analytical cohort.

In the analytical cohort, univariate analysis was performed for qualitative variables by a mixed-model of country and reported as odds ratios (OR) with $95 \%$ confidence interval (CI). Mixed-logistic regression models were adjusted by backward-stepwise regression based on the maximum likelihood estimators and median OR was estimated for the countries effect. The likelihood-ratio and its significance were calculated for each variable according to criteria for entry $(p<0.05)$ and removal $(p>0.10)$. We selected risk factors either showing a $p<0.10$ in the univariate analysis or that were clinically relevant. Possible collinearity and interactions were evaluated with the introduction of multiplicative terms.

Discriminative capacity was assessed by the area under the ROC curve (AUC) and its 95\% CI. The model was calibrated by comparing predicted versus observed probabilities after their calculation from the adjusted model coefficients. The Hosmer-Lemeshow test was used for model goodnessof-fit. The model with the greatest discriminative power, good calibration, viable capacity, and meeting the principle of parsimony, explaining the maximum variability outcome variable with the smallest number of parameters included, was selected. Internal validity was assessed with bootstrap of 1000 samples and optimistic value was reported.

A mortality risk-score was obtained from the point estimate for each variable using the OR of the final model. Predicted and observed probabilities were compared. AUCs of the scores were compared with the nonparametric ROC Mann-Whitney $U$ test.
We performed a propensity-score matching (PSM), estimated by $t$ effects psmatch, to determine how near subjects were to each other by using estimated treatment probabilities. Variables included in the PSM were those identified by the multivariate analysis. In all cases, the distribution of the variable was checked against theoretical models and the assumption of homogeneity of variance tested. In all hypothesis tests the null hypothesis with a type I error or $\alpha$ error $<0.05$ was rejected. The statistical packages used were SPSS 24.0 (SPSS Inc, Chicago, IL) and STATA 15.0 (StataCorp LLC, College Station, TX). The manuscript was drafted following the TRIPOD statement [6].

\section{Results}

\section{Characteristics of the patients and in-hospital outcomes: descriptive cohort.}

1021 patients were finally included in HOPE registry on 2 April 2020, from 23 centers in 19 cities and 4 countries (Ecuador, Germany, Italy and Spain), Fig. 1. Between 8 February and 1 April, of those, 311 died during hospitalization and 710 were discharged alive.

The median age was 68 years (IQR 52.0-79.0), and most were male $(59.5 \%)$. The most frequent comorbidities were hypertension (46.8\%) and dyslipidemia (35.8\%). Concerning other conditions, a relevant heart or lung disease were depicted in $20 \%$, and any renal, cerebrovascular or oncological disease were reported in 8.2, 9.7 and 13.3\%. Further details are displayed, stratified by vital status, and the need of invasive mechanical ventilation, in appendix table S1.
Fig. 1 Study patient flow diagram

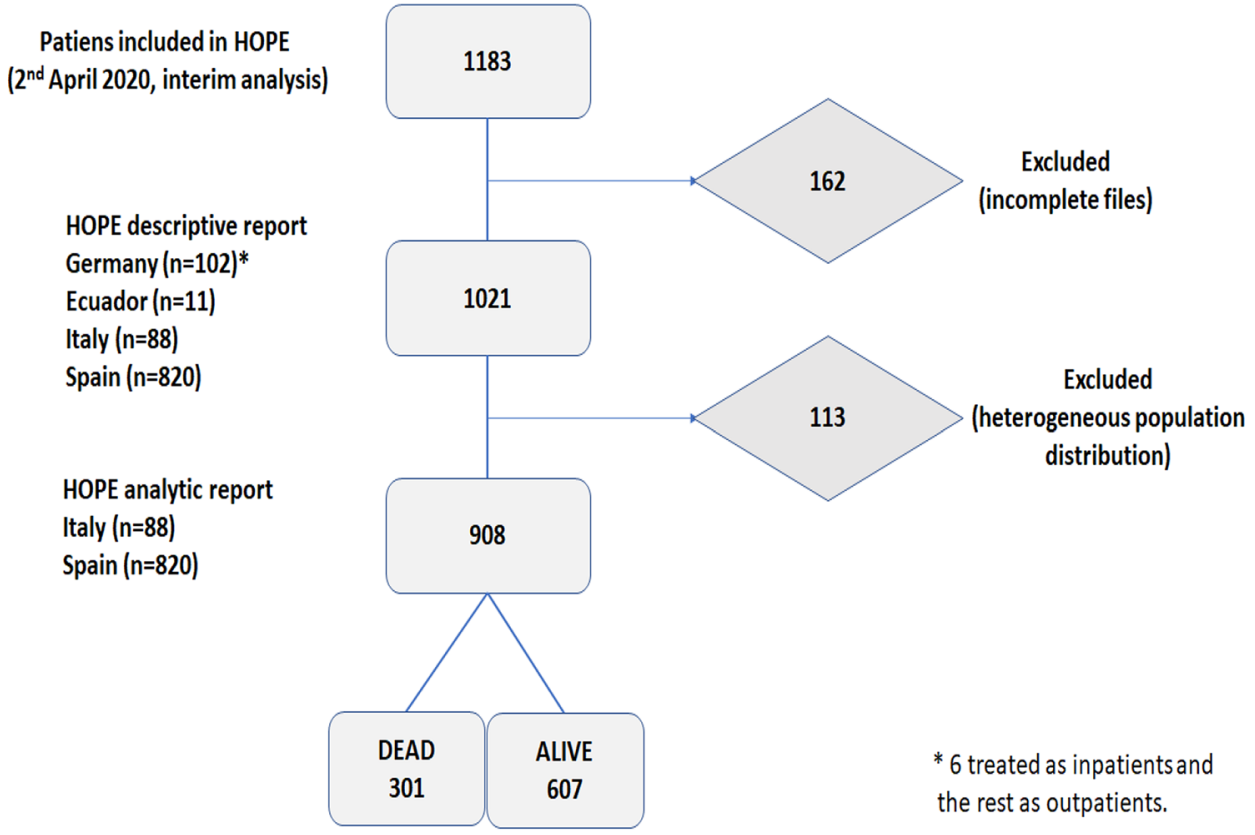


The most common presentation symptoms on admission were fever $(78.2 \%)$, cough and dyspnea in more than $50 \%$, with low transcutaneous oxygen saturation by pulse oximetry $(<92 \%)$ in $38 \%$. Other symptoms, less frequent but striking, were diarrhea (17.5\%), vomiting (7.6\%), hypo/anosmia and dysgeusia (10\%), confusion (Glasgow coma score $<15$ : $8 \%)$ and syncope $(<1 \%)$.

In the exploratory field, tachypnea was reported in $26 \%$ and $8 \%$ showed abnormally low blood pressure. At the time of hospital admission, blood tests highlighted an elevated C-reactive protein $(92 \%)$, lactate dehydrogenase $(75.5 \%)$,
D-dimer (67\%), and ferritin (60\%) levels. Chest X-ray revealed acute lung abnormalities in more than $70 \%$, mostly bilateral.

Overall management is depicted in Table 1. The specific drug most frequently used was hydroxychloroquine (72\%), followed by antibiotics and an antiviral drug (mostly lopinavir/ritonavir, excepting in three cases: oseltamivir), in more than $60 \%$.

In the respiratory sphere, prone was used in $10 \%$, and non-invasive mechanical ventilation in $16 \%$. An invasive ventilation approach was reached in $5.3 \%$ (49/916). Of those,

Table 1 Medical management and in-hospital stay of the registry participants overall (descriptive cohort), based on attending physician team criteria

$\begin{array}{lll}\text { All patients }^{\mathrm{a}}(n=1021) & \text { Vital Status }^{\mathrm{b}} & \text { Invasive mechanical ventilation } \\ & \text { Death }=311 / 1021(30) & \text { All, } n=916^{\mathrm{a}} \text { yes }=49(5.3)^{\mathrm{b}}\end{array}$

\section{Management}

Non-invasive mechanical ventilation

\begin{tabular}{|c|c|c|c|c|}
\hline Yes & $157 / 955(16.4)$ & $80 / 301(51)$ & $138 / 906(15.2)$ & $15 / 46(10.9)$ \\
\hline No & 798/955 (83.6) & $221 / 301(27.7)$ & $768 / 906(84.8)$ & $31 / 46(4)$ \\
\hline \multicolumn{5}{|l|}{ rone during admission } \\
\hline Yes & 92/933 (9.9) & $61 / 297(66.3)$ & 82/884 (9.3) & $21 / 44(25.6)$ \\
\hline No & $841 / 933(90.1)$ & $236 / 297(28.1)$ & $802 / 884(90.7)$ & $23 / 44(2.9)$ \\
\hline \multicolumn{5}{|l|}{ Jse of corticoids } \\
\hline Yes & $183 / 939(19.5)$ & $99 / 304(54.1)$ & $171 / 890(19.2)$ & $17 / 43(9.9)$ \\
\hline No & $756 / 939(80.5)$ & $205 / 304(27.1)$ & $719 / 890(80.8)$ & $26 / 43(3.6)$ \\
\hline \multicolumn{5}{|l|}{ Hydroxicloroquine } \\
\hline Yes & 686/954 (71.9) & $200 / 300(29.2)$ & $644 / 899(71.6)$ & $41 / 48(6.4)$ \\
\hline No & 268/954 (28.1) & $100 / 300(37.3)$ & $255 / 899(28.4)$ & $7 / 41(2.7)$ \\
\hline \multicolumn{5}{|l|}{ Antiviral drugs } \\
\hline Yes & $585 / 957(61.1)$ & $172 / 299(29.4)$ & $545 / 897(60.8)$ & $38 / 48(7)$ \\
\hline No & 372/957 (38.9) & $127 / 299(34.1)$ & $352 / 897(39.2)$ & $10 / 48(2.8)$ \\
\hline \multicolumn{5}{|l|}{ nterferon or similar } \\
\hline Yes & $120 / 932(12.9)$ & $59 / 296(49.2)$ & $113 / 887(12.7)$ & $14 / 46(12.4)$ \\
\hline No & $812 / 932(87.1)$ & $237 / 296(29.2)$ & $774 / 887(87.3)$ & $32 / 46(4.1)$ \\
\hline \multicolumn{5}{|l|}{ Tocilizumab or similar } \\
\hline Yes & $48 / 929(5.2)$ & $24(50)$ & $46 / 884(5.2)$ & $14 / 49(30.4)$ \\
\hline No & $881 / 929(94.8)$ & $267(30.3)$ & $838 / 884(94.8)$ & $35 / 49(4.2)$ \\
\hline \multicolumn{5}{|l|}{ Antibiotics } \\
\hline Yes & 635/962 (66) & $237 / 306(37.3)$ & $591 / 906(65.2)$ & $46 / 49(7.8)$ \\
\hline No & $327 / 962(34)$ & $69 / 306(21.1)$ & $315 / 906(34.8)$ & $3 / 49$ (1) \\
\hline \multicolumn{5}{|l|}{ Jse of ACEis/ARBs during instay } \\
\hline Yes & $120 / 880(13.6)$ & $31 / 277(25.8)$ & $115 / 852(13.5)$ & $7 / 43(6.1)$ \\
\hline \multirow[t]{2}{*}{ No } & $760 / 880(86.4)$ & $246 / 277(32.4)$ & $737 / 852(86.5)$ & $36 / 43(4.9)$ \\
\hline & All patients ${ }^{\mathrm{b}}(n=1021)$ & $\begin{array}{l}\text { Vital Status }^{\mathrm{b}} \\
(n=1021) \\
\text { Death }=311(30 \%) \\
\text { Alive }=710(70 \%)\end{array}$ & \multicolumn{2}{|c|}{$\begin{array}{l}\text { Mechanical ventilation }{ }^{\mathrm{b}}(N=916) \\
\text { Yes }=49(5.3) \mathrm{No}=867(94.7)\end{array}$} \\
\hline $\begin{array}{l}\text { Median symptoms to admission, (IQR)- } \\
\text { days }\end{array}$ & $5(3-8)$ & $3(2-6)$ & $5(3-8)$ & $4(3-7)$ \\
\hline Median in-hospital stay, (IQR)-days & $5(2-8)$ & $5(2-8)$ & $5(2-8)$ & $7(2-11.5)$ \\
\hline
\end{tabular}

${ }^{\text {a }}$ Some data are missing at the time of interim analysis. Calculations and percentages are expressed upon the recorded data as are displayed in the table (recorded/total)

${ }^{\mathrm{b}}$ In vital status and invasive mechanical ventilation, percentages are related to the presence or not of the event in that characteristic 
$73.5 \%$ died (36/49). Regarding other events, the most common was a bilateral pneumonia, in more than $75 \%$ of the cases, with respiratory insufficiency in $45 \%$. Renal failure, sepsis or systemic inflammatory response syndrome (SIRS) were common, in more than 15\%, Fig. 2. Over 311 patients demised during their admission, the most frequent cause, according to the attending physician criteria, was respiratory followed by sepsis/SIRS or combined in more than $92 \%$.

\section{Mortality risk assessment: analytic cohort}

All countries specific features are stratified in appendix. The analytical cohort median age was 70 years (IQR 56-81), $59.6 \%$ were male and $92 \%$ Caucasian. The most frequent comorbidities were hypertension $(51.3 \%)$, dyslipidemia (40\%), obesity (23.5\%) and diabetes (19.5\%). A complete univariate analysis of this cohort, with corresponding ORs, is provided in the appendix, tables S2-S10.

Age, hypertension, obesity, renal insufficiency, any immunosuppressive disease, 02 saturation $<92 \%$ and an elevated C-reactive protein were the most relevant risk-factors for death in the logistic regression model, Table 2. The model displayed good discrimination $(\mathrm{AUC}=0.87)$, internal validation (bootstrap, optimist 0.0018) and calibration (Hosmer-Lemeshow test, $p>0.999$ ).
The weight of every variable changed depending on the age stratum we were considering. Thus, for the younger cohort ( $<70$ years), obesity and immunosuppression seemed to be more important, while hypertension was more relevant in the senior cohort. Renal insufficiency and desaturation remained important in both. With all, we produced a risk score to estimate probability of death, dividing patients in four groups of growing mortality (I-IV), Table 2.

\section{Drugs findings}

Addressing the effect of the different drugs, see appendix, we consider our results only exploratory, taking into account the design of this study. The drugs included hydroxychloroquine (79.2\%) and antivirals (67.6\%), which were frequently used in the analytic cohort. The univariate assessment pointed to a raw favorable effect for these treatments $\left(\mathrm{OR}_{\text {hydroxychloroquine }}\right.$ $0.43,95 \%$ CI $0.24-0.48, p<0.001 ; \mathrm{OR}_{\text {antiviral }} 0.53,95 \% \mathrm{CI}$ $0.40-0.72, p<0.001)$.

Therefore, we performed a PSM-adjustment using the relative variables for mortality already mentioned. The results suggested a slight improvement in mortality rates (PSM-adjusted $\mathrm{OR}_{\text {hydroxychloroquine }} 0.88 ; 95 \%$ CI 0.81-0.91, $p=0.005 ;$ PSM-adjusted $\mathrm{OR}_{\text {antiviral }} 0.94 ; 95 \%$ CI $0.87-1.01$; $p=0.115$ ).

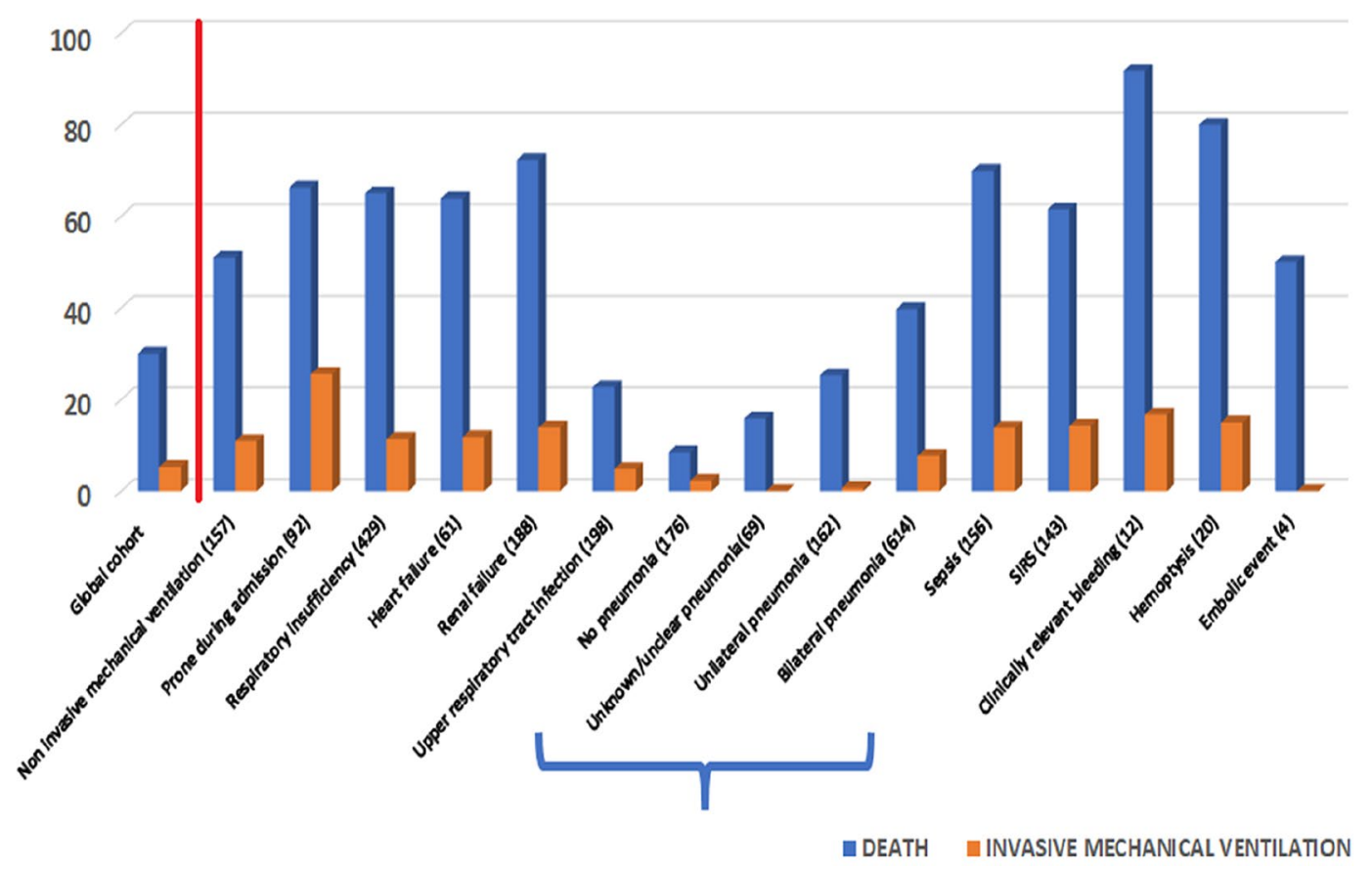

Fig. 2 Percentages ( $y$ axis) of death (blue bar) and invasive mechanical ventilation (orange bar) stratified by in-hospital events. In brackets, the raw numbers of patients with that complication, in the descriptive cohort (color figure online) 


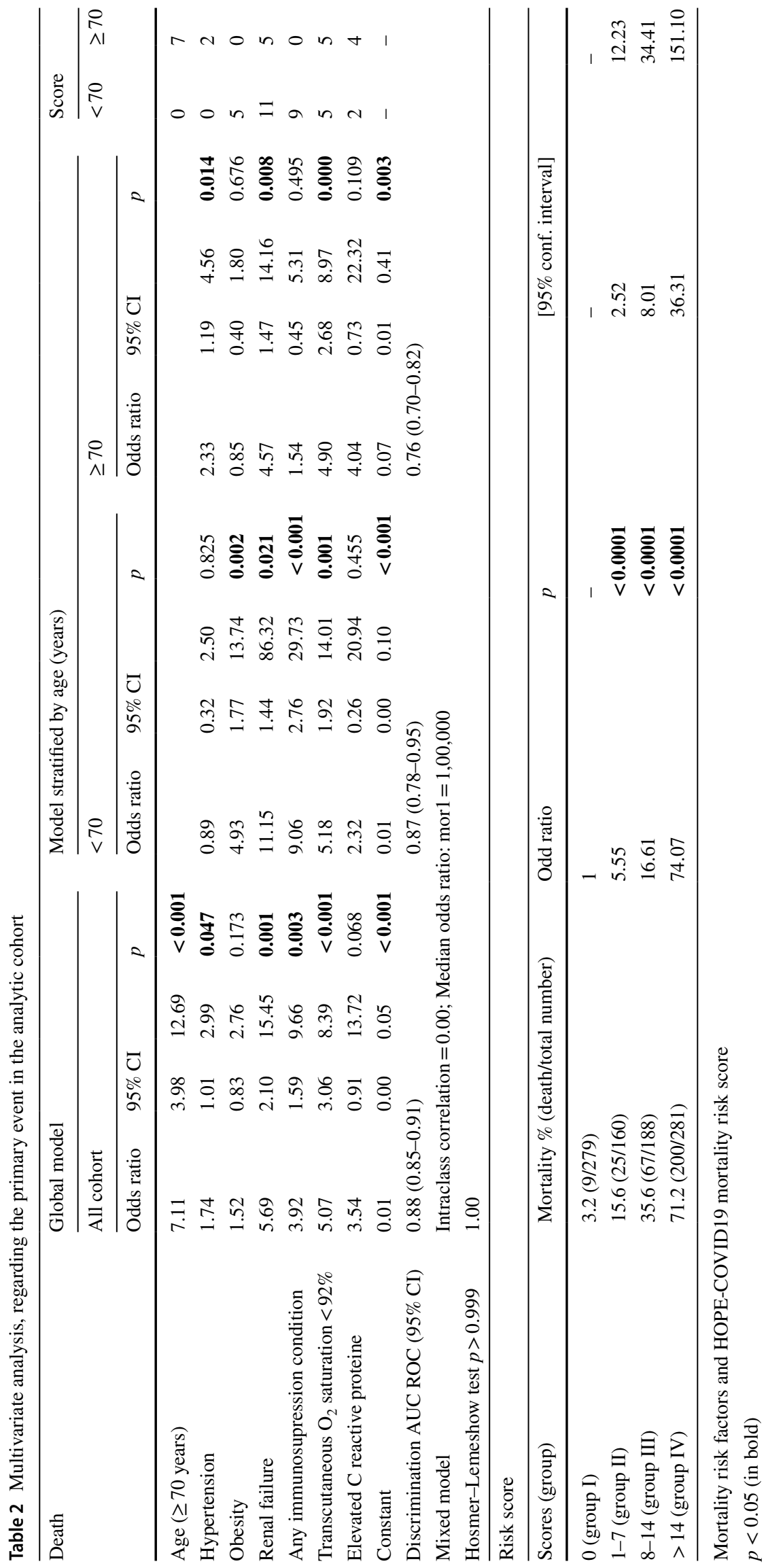




\section{Discussion}

To the best of our knowledge, this is one of the larger multinational cohort studies among patients with COVID-19 after discharge.

A relevant finding of our study is the decisive influence of age on SARS-CoV2 mortality. This is not novel, as it has been associated with COVID-19 mortality in series from China [7, 8] and Italy [9].

In addition, we must highlight the importance of comorbidities in the prognosis in our series [10, 11]. Specifically, we identified hypertension, obesity, kidney failure or immunosuppression status as significant factors. Interestingly, these risk factors seemed modulated by age. For example, hypertension is associated with an increased risk of death in older people but not so in those under 70 years of age. In the same way, suffering from an immunosuppressive condition was associated with mortality in patients under 70 .

Aging is associated with increased disease susceptibility, reduced capacity to overcome acute stress and negatively influences innate and adaptive immunity. These changes might justify a worse prognosis after SARS-CoV2 infection. In animal models of SARS-CoV [12] no differences were found in viral replication levels when comparing aged and young adult macaques; however, the host response to infection is stronger in aged animals, suggesting that aging is associated with an increased severity in pro-inflammatory responses. A cross-talk between antiviral responses and pro-inflammatory pathways modulated by age has been proposed [12]. This balance between transcription factors could affect the infection outcome in such a way that an exuberant host response is responsible for the severe inflammation of the lung and development of acute respiratory distress syndrome.

Hypertension has been identified in other studies as risk factor for hospitalization and ICU admission in COVID-19 $[13,14]$. It may be associated to structural heart disease and added to the hypothetical viral direct effect on the cardiomyocyte or myositis. Both could justify the observed high rate of mortality associated with hypertension. The existence of myocardial infection has been documented in animal models with SARS-CoV infection. Likewise, SARS-CoV viral RNA was detected in 35\% of autopsied human heart samples during the Toronto SARS outbreak [15]. In a case-series of 416 hospitalized patients with COVID-19, patients with cardiac injury had higher mortality than those without it [16]. In our series, an elevated troponin level pointed to an increased, non-adjusted mortality (OR 2.95; 95\% CI 1.74-5.01; $p<0.001$ ).

Another recognized risk factor, for hospitalization and mechanical ventilation in 2009 influenza A (H1N1) infection was obesity [17]. In addition, the Centers for Disease Control and Prevention consider those with $\mathrm{BMI} \geq 40 \mathrm{~kg} / \mathrm{m}^{2}$ at risk for flu complications [18]. Obese individuals may be at higher risk for pneumonia [19]. So far, the effect of obesity on the risk of complications from COVID-19 has not been described. In a Chinese series, this absence of relationship could be related to a lower prevalence of obesity compared to Western-Europe [20]. In our series, we found a significant association of obesity with mortality only in patients under the age of 70 . Obesity is a risk factor for many chronic diseases and could produce an effect through due to its influence on lung ventilatory mechanics.

Kidney disease has been described as a risk factor for mortality in COVID-19 [21]. SARS-Cov2 may have direct cytopathic effects on kidney tissue [22], entering kidney cells through an angiotensin converting enzyme (ACE)-2 dependent pathway. Also, an immune-mediated damage related to virus-induced immune complexes has been reported [23]; the systemic inflammatory response observed in COVID-19 can exert indirect effects on kidney tissue, such hypoxia, shock, and rhabdomyolysis. Autopsy studies of patients with COVID-19 did not find firm evidence of SARS-CoV2 infection in the kidney [23]. The observed kidney damage consisted of changes in glomerular endothelial and tubular-epithelial cells which could be related to the severity of inflammatory response.

We have identified the condition of previous immunosuppression as a risk factor of increased mortality, mostly in the group $<70$ years. Its role in susceptibility to SARS$\mathrm{CoV} 2$ infection is unknown, but it is worrying that it could facilitate the development of severe infection. An exaggerated inflammatory response could worsen the prognosis of the disease [24]. Therefore, immunosuppression could be a double-edged sword [25]; on the one hand, it might reduce the inflammatory response but at the same time it could facilitate the persistence of viral replication. Thus, the use of anti-inflammatory or immunomodulatory drugs should be considered together with specific antiviral drugs.

In this study, we proposed various prognostic factors associated with mortality which are easy to obtain in routine practice everywhere, such as low oxygen saturation or elevated CRP. Along with the aforementioned clinical data, we provided a score that may have clinical applicability to identify patients with a graded prognosis, useful in most all environments. Thus, for those patients who present high scores (above 14 points) the risk of death is close to $75 \%$. With this tool, we provide an online mortality risk calculator (https://www.hopeprojectmd.com/en/tool).

In a preliminary evaluation of the association of treatment effects on mortality through a PSM, we found that hydroxychloroquine was associated with a reduction in the risk of death. Together with the biological plausibility of 
the effect of hydroxychloroquine through its antiviral [26], immunomodulatory effect [27] and preliminary results of its clinical benefit [28], our data support its use until the existence of definitive data is available in severe cases. In contrast, we have not identified with this same analysis a significant benefit of antivirals, in most cases lopinavir/ritonavir, according to published clinical trials with this drug [29].

\section{Limitations}

We need to consider the constraints of a study of this design. Some incident events in the participating centers may not have been diagnosed and/or not been reported. The events incidence calculation is not precise since the recruitment was performed in participating centers without any other sampling procedure than the broad inclusion criteria (hospital discharge) and would vary depending on the patient's, hospital, country or local pandemic curve. Finally, the data analysis and modeling focused on only two countries (Italy and Spain) of the four initially considered, since as previously mentioned heterogeneity among countries with regard to clinical features and death-risk assessment could limit the representative nature of the sampling.

Regarding the clinical management applied, it was decided at all times by the attending medical team. While these observations give us with an overall idea of the treatment of the disease in a precise time and in specific countries, they do not provide information that is as robust as a clinical trial would do.

On the basis of the disease assessed in this paper, we can only generate hypotheses regarding therapeutics; nevertheless, HOPE present interim analysis probably reveals a realistic depiction of the results and the contemporary real-life prognosis of patients who are admitted with COVID-19 in Italy and Spain.

\section{Conclusions}

COVID-19 produces important mortality, mostly in patients with comorbidities and respiratory symptoms. Some simple clinical and analytically broadly available features were able to predict most of the observed deaths in the present cohort. Hydroxychloroquine could be associated with survival benefit, but this data need to be confirmed with prospective trials.

Acknowledgements Cardiovascular excellence SL, for their essential support in the database and HOPE webpage. All HOPE researchers. Ms. Elena Kneip for her kind help as language reviewer.

Author contributions ING, CFS and VE designed and analyzed the data. ING, CFS, VE, AFO, CM drafted the manuscript. All of the other collaborators lead the registry in their respective centers and enrolled patients. The order of authorship was determined upon recruitment and
HOPE involvement. Finally, all authors had full access to the manuscript and agree with it.

Funding Non-conditioned grant (FUNDACIÓN INTERHOSPITALARIA PARA LA INVESTIGACIÓN CARDIOVASCULAR, FIC. Madrid, Spain). This nonprofit institution had no role in the study design; in the collection, analysis, interpretation of data; in the writing of the report; nor in the decision to submit the paper for publication.

\section{Compliance with ethical standards}

Conflict of interest The author(s) declare that they have no conflict of interest.

Statements on human and animal rights Our study was performed in accordance with the ethical standards of our institutional (Hospital Clinico San Carlos, Spain) and with the 1964 Helsinki Declaration and its later amendments or comparable ethical standards.

Informed consent Written informed consent was waived by a central ethics committee, considering this an anonymized observational study in a pandemic situation.

\section{References}

1. WHO. WHO statement regarding cluster of pneumonia cases in Wuhan, China. https://www.who.int/china/news/detail/09-012020-who-statement-regarding-cluster-of-pneumonia-cases-inwuhan-china. Accessed 27 Apr 2020

2. WHO. https://www.euro.who.int/en/health-topics/health-emerg encies/coronavirus-covid-19/news/news/2020/3/who-announcescovid-19-outbreak-a-pandemic. Accessed 27 Apr 2020

3. Dong E, Du H, Gardner L (2020) Aninteractive web-baseddashboardtotrackCOVID-19 in real time. LancetInfectDis 20:533-534

4. Guan WJ, Ni ZY, Hu Y, Liang WH, Ou CQ, He JX (2020) Clinicalcharacteristics of coronavirus disease 2019 in China. N Engl J Med. https://doi.org/10.1056/NEJMoa2002032

5. WHO. https://www.who.int/emergencies/diseases/novel-coron avirus-2019. Accesed 27 Apr 2020

6. Collins GS, Reitsma JB, Altman DG, Group T (2015) Transparent reporting of a multivariable prediction model for individual prognosis or diagnosis (TRIPOD): the TRIPOD statement. The TRIPOD Group. Circulation 131:211-219

7. Wu Z, McGoogan JM (2020) Characteristics of and importantlessonsfromthe coronavirus disease 2019 (COVID-19) outbreak in China: summary of a report of 72314 cases fromtheChinese Center forDisease Control and Prevention. JAMA 323:1239-1242

8. Zhou F, Yu T, Du R, Fan G, Liu Y, Liu Z et al (2020) Clinical course and risk factors for mortality of adult inpatients with COVID-19 in Wuhan, China: a retrospective cohort study. Lancet 395(10229):1054-1062

9. Onder G, Rezza G, Brusaferro S (2020) Case-fatalityrate and characteristics of patientsdying in relationtoCOVID-19 in Italy. JAMA 323:1775-1776

10. Yang J, Zheng Y, Gou X, Pu K, Chen Z, Guo Q, Ji R, Wang H, Wang Y, Zhou Y (2020) Prevalence of comorbidities and its effects in patients infected with SARS-CoV-2: a systematic review and meta-analysis. Int J Infect Dis 94:91-95

11. Wang T, Du Z, Zhu F, Cao Z, An Y, Gao Y et al (2020) Comorbidities and multi-organ injuries in the treatment of COVID-19. Lancet 395(10228):e52 
12. Smits SL, de Lang A, van den Brand JM, Leijten LM, van Ijcken WF, Eijkemans MJ et al (2010) Exacerbatedinnate host response toSARS-CoV in aged non-human primates. PLoSPathog. 6(2):e1000756

13. Emami A, Javanmardi F, Pirbonyeh N, Akbari A (2020) Prevalence of underlying diseases in hospitalized patients with COVID19: a systematic review and meta-analysis. Arch AcadEmerg Med 8(1):e35

14. Li B, Yang J, Zhao F, Zhi L, Wang X, Liu L et al (2020) Prevalence and impact of cardiovascular metabolicdiseasesonCOVID-19 in China. Clin Res Cardiol 101:531-538

15. Oudit GY, Kassiri Z, Jiang C, Liu PP, Poutanen SM, Penninger JM et al (2009) SARS-coronavirus modulation of myocardial ACE2 expression and inflammation in patients with SARS. Eur J ClinInvestig 39(7):618-625

16. Shi S, Qin M, Shen B, Cai Y, Liu T, Yang F et al (2020) Association of cardiac injury with mortality in hospitalized patients with COVID-19 in Wuhan. China. JAMA Cardiol 5:802-810

17. Louie JK, Acosta M, Winter K, Jean C, Gavali S, Schechter R et al (2009) Factors associated with death or hospitalization due to pandemic 2009 influenza $\mathrm{A}(\mathrm{H} 1 \mathrm{~N} 1)$ infection in California. JAMA 302(17):1896-1902

18. Centers for Disease Control and Prevention (CDC). People at high risk for flu complications. https://www.cdc.gov/flu/highrisk/index .htm. Accesed 29 Oct 2020

19. Nie W, Zhang Y, Jee SH, Jung KJ, Li B, Xiu Q (2014) Obesity survival paradox in pneumonia: a meta-analysis. BMC Med 12:61

20. CollaborationNCDRF (2016) Trends in adult body-mass index in 200 countries from 1975 to 2014: a pooled analysis of 1698 population-based measurement studies with 19.2 million participants. Lancet 387(10026):1377-1396

21. Cheng Y, Luo R, Wang K, Zhang M, Wang Z, Dong L et al (2020) Kidney disease is associated with in-hospital death of patients with COVID-19. Kidney Int 97:829-838
22. Huang C, Wang Y, Li X, Ren L, Zhao J, Hu Y et al (2020) Clinical features of patients infected with 2019 novel coronavirus in Wuhan, China. Lancet 395(10223):497-506

23. Yao XH, Li TY, He ZC, Ping YF, Liu HW, Yu SC et al (2020) A pathological report of three COVID-19 cases by minimally invasive autopsies. Zhonghua Bing Li XueZaZhi 49:E009

24. Mehta P, McAuley DF, Brown M, Sanchez E, Tattersall RS, Manson JJ et al (2020) COVID-19: consider cytokine storm syndromes and immunosuppression. Lancet 395(10229):1033-1034

25. Ritchie AI, Singanayagam A (2020) Immunosuppression for hyperinflammation in COVID-19: a double-edged sword? Lancet 395(10230):1111

26. Wang M, Cao R, Zhang L, Yang X, Liu J, Xu M et al (2020) Remdesivir and chloroquine effectively inhibit the recently emerged novel coronavirus (2019-nCoV) in vitro. Cell Res 30(3):269-271

27. Lee SJ, Silverman E, Bargman JM (2011) The role of antimalarial agents in the treatment of SLE and lupus nephritis. Nat Rev Nephrol 7(12):718-729

28. Cortegiani A, Ingoglia G, Ippolito M, Giarratano A, Einav S (2020) A systematic review on the efficacy and safety of chloroquine for the treatment of COVID-19. J Crit Care 57:279-283

29. Cao B, Wang Y, Wen D, Liu W, Wang J, Fan G et al (2020) A trial of Lopinavir-Ritonavir in adults hospitalized with severe Covid19. N Engl J Med 382:1787-1799

Publisher's Note Springer Nature remains neutral with regard to jurisdictional claims in published maps and institutional affiliations.

\section{Affiliations}

Iván J. Núñez-Gil ${ }^{1}$. Cristina Fernández-Pérez ${ }^{9,24}$. Vicente Estrada ${ }^{1} \cdot$ Víctor M. Becerra-Muñoz ${ }^{2}$. Ibrahim El-Battrawy ${ }^{3}$ - Aitor Uribarri ${ }^{4} \cdot$ Inmaculada Fernández-Rozas ${ }^{5}$. Gisela Feltes ${ }^{6}$. María C. Viana-Llamas ${ }^{7}$. Daniela Trabattoni ${ }^{8}$. Javier López-País ${ }^{9} \cdot$ Martino Pepe $^{10} \cdot$ Rodolfo Romero $^{11}$ - Alex F. Castro-Mejía ${ }^{12}$. Enrico Cerrato ${ }^{13,27}$. Thamar Capel Astrua ${ }^{14}$. Fabrizio D'Ascenzo ${ }^{15}$. Oscar Fabregat-Andres ${ }^{16}$. José Moreu ${ }^{17}$. Federico Guerra ${ }^{18}$. Jaime Signes-Costa ${ }^{19}$. Francisco Marín ${ }^{20,26}$. Danilo Buosenso ${ }^{21}$. Alfredo Bardají ${ }^{22}$. Sergio Raposeiras-Roubín ${ }^{23}$. Javier Elola ${ }^{24}$. Ángel Molino ${ }^{1}$. Juan J. Gómez-Doblas ${ }^{2}$. Mohammad Abumayyaleh ${ }^{3}$. Álvaro Aparisi ${ }^{4} \cdot$ María Molina $^{5} \cdot$ Asunción Guerri $^{6} \cdot$ Ramón Arroyo-Espliguero $^{7}$. Emilio Assanelli ${ }^{8}$. Massimo Mapelli ${ }^{8,25}$. José M. García-Acuña ${ }^{9} \cdot$ Gaetano Brindicci $^{10}$ - Edoardo Manzone ${ }^{11} \cdot$ María E. Ortega-Armas $^{12}$. Matteo Bianco ${ }^{13}$. Chinh Pham Trung ${ }^{14}$. María José Núñez ${ }^{1}$. Carmen Castellanos-Lluch ${ }^{19}$. Elisa García-Vázquez ${ }^{20,26}$. Noemí Cabello-Clotet ${ }^{1} \cdot$ Karim Jamhour-Chelh ${ }^{23} \cdot$ María J. Tellez $^{1} \cdot$ Antonio Fernández-Ortiz $^{1} \cdot$ Carlos Macaya $^{1}$ on behalf of HOPE COVID-19 Investigators

Iván J. Núñez-Gil

ibnsky@yahoo.es

1 Hospital Clínico San Carlos, Universidad Complutense de Madrid, Instituto de Investigación Sanitaria del Hospital Clínico San Carlos (IdISSC), Prof Martin Lagos St., 28040 Madrid, Spain

2 Unidad de Gestión Clínica Área del Corazón, Instituto de Investigación Biomédica de Málaga (IBIMA), Hospital Universitario Virgen de La Victoria, Universidad de Málaga
(UMA), Centro de Investigación Biomédica en Red de Enfermedades Cardiovasculares (CIBERCV), Málaga, Spain

3 University Mannheim, Mannheim, Germany

4 Hospital Clínico Universitario de Valladolid, Valladolid, Spain

5 Hospital Severo Ochoa, Leganés, Spain

6 Hospital Nuestra Señora de América, Madrid, Spain

7 Hospital Universitario Guadalajara, Guadalajara, Spain 
8 Centro Cardiologico Monzino, IRCCS, Milan, Italy

9 Complejo Hospitalario Universitario de Santiago de Compostela, Santiago de Compostela, Spain

10 Azienda Ospedaliero-Universitaria Consorziale Policlinico Di Bari, Bari, Italy

11 Hospital Universitario Getafe, Madrid, Spain

12 Hospital General del Norte de Guayaquil IESS Los Ceibos, Guayaquil, Ecuador

13 Cardiology Division, San Luigi Gonzaga University Hospital, Orbassano, Turin, Italy

14 Hospital Virgen del Mar, Madrid, Spain

15 San Giovanni Battista, Turin, Italy

16 Hospital IMED, Valencia, Spain

17 Complejo hospitalario de Toledo, Toledo, Spain

18 Cardiology and Arrhythmology Clinic, Ospedali Riuniti "Umberto I-Lancisi-Salesi", Ancona, Italy
19 Hospital Clínico Universitario, Incliva, Universidad de Valencia, Valencia, Spain

20 Hospital Clinico Universitario Virgen de la Arreixaca, Murcia, Spain

21 Department of Woman and Child Health and Public Health, Fondazione Policlinico Universitario A. Gemelli IRCCS, Rome, Italy

22 University Hospital Joan XXIII, Tarragona, Spain

23 University Hospital Álvaro Cunqueiro, Vigo, Spain

24 Fundación Instituto para la Mejora de la Asistencia Sanitaria (IMAS), Madrid, Spain

25 Department of Clinical Sciences and Community Health, Cardiovascular Section, University of Milan, Milan, Italy

26 IMIB-Arreixaca, Universidad de Murcia, Murcia, Spain

27 Rivoli Infermi Hospital, Rivoli, Turin, Italy 